\title{
THE $1,4 \mathrm{C} \rightarrow \mathrm{O}$ SILYL MIGRATIONS OF VARIOUS FURAN AND THIOPHENE SYSTEMS
}

\author{
Patrick G. Spinazzé and Brian A. Keay* \\ Department of Chemistry and Biochemistry \\ University of Windsor, Windsor, Ontario, Canada, N9B 3P4
}

SUMMARY: 2-Trialkylsilyl-3-hydroxymethyl-furans and -thiophenes undergo a 1,4 C $\rightarrow \mathrm{O}$ sily1 migration when treated with bases containing either potassium or sodium counterions to produce 3-[(trialkylsilyl)oxymethyl]furans and -thiophenes in excellent yields.

We have shown that 3-[(t-butyldimethylsilyl)oxymethyl]furan 20, when treated with n-butyllithium/HMPA, undergoes rare a $1,4 \mathrm{O} \rightarrow \mathrm{C}$ silyl migration producing 2-t-butyldimethylsilyl-3-hydroxymethylfuran $\underline{6}$ (Scheme 1). ${ }^{1}$ When furan 6 was lithiated with 2 equivalents of n-butyllithium, ring lithiation occurred exclusively at C-4; trapping the C-4 anion with various electrophiles yielded 2-silyl-3,4-disubstituted furans 29 which upon de lylation provided a facile route to various 3,4-disubstituted furans. ${ }^{2}$

In a synthetic application of this methodology we required the protection of the hydroxymethyl group in $\underline{29}$ by a $t$-butyldimethylsilyloxy group. Due to the high cost of $\mathrm{t}$-butyldimethylsilyl chloride and since the synthesis did not require a group in the 2-position of the furan ring, we sought a method of performing a 1,4 $\mathrm{C} \rightarrow \mathrm{O}$ silyl migration in systems like 29. Treatment of $\underline{29}$ with sodium hydride in either THF or DMF easily achieved this transformation (Scheme 1). As $1,4 \mathrm{C} \rightarrow \mathrm{O}$ silyl migrations are rare $^{3}$ we decided to investigate this reaction, and herein we report our findings.

SCHEME 1

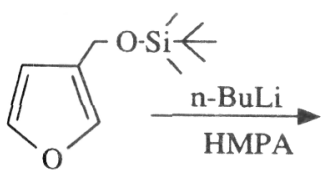

$\underline{20}$

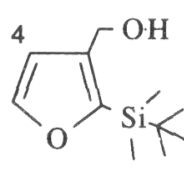

6

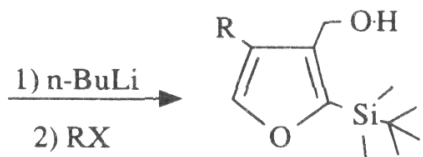

29

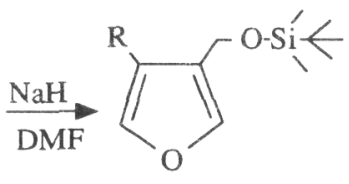

$\underline{30}$

The reaction was limited neither to the t-butyldimethylsilyl group nor to furans as evident by the many examples shown in Table 1. The yields are generally high for furans and thiophenes in both DMF and THF. Although the times listed for the reaction in DMF are 1 hour, they were essentially complete within 5 minutes (by tlc). Some of the silyloxy groups formed were found to be labile under the conditions employed providing 3-(hydroxymethyl)furan in high yield (entries 8, 11-13); however, 3-[(triethylsilyl)oxymethyl]furan 22 could be isolated if the reaction (in DMF) was worked up after 5 minutes. The silyl migration tolerates various groups at the C-4 position of the furan ring (entries $9,10 \& 14$ ) and is not limited to primary alcohols at the C-3 position (entry 14). The t-butyldimethylsilyl group in furan 14 smoothly migrated to the secondary alcohol (at C-3) in the presence of a C -4 allyl moiety (entry 14 ). 
$\underline{T A B L E} \underline{1} \quad 1,4 \mathrm{C} \rightarrow \mathrm{O}$ Silyl Migration Conditions and Yields

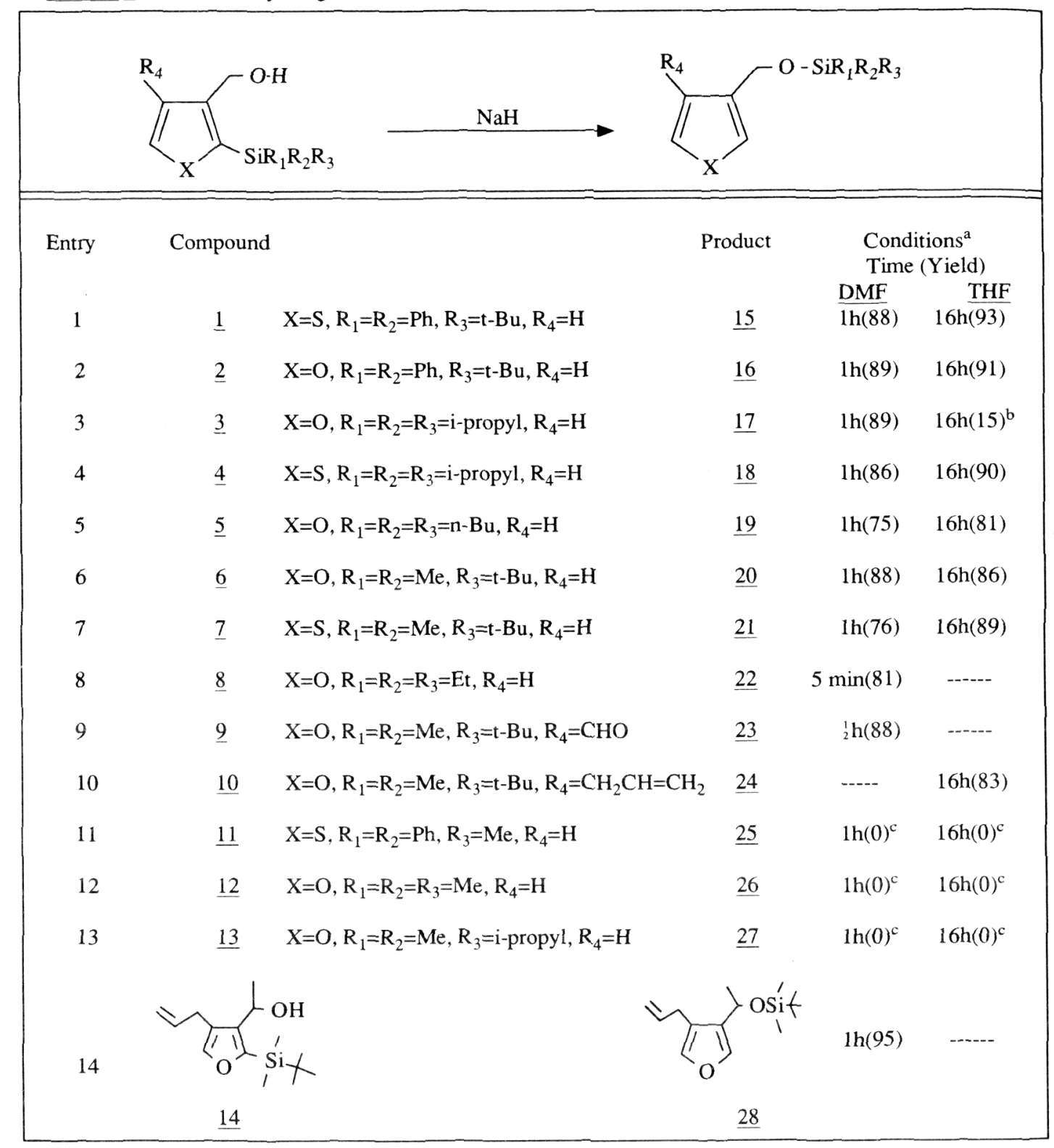

a) All reactions were performed using 5 equivalents of $\mathrm{NaH}$ at a $0.05 \mathrm{M}$ starting material concentration.

b) 70\% of 3-hydroxymethylfuran was also recovered.

c) None of the silyloxy product was obtained. Only 3-hydroxymethylfuran was recovered in excellent yield (>90\%). 
TABLE 2 The Effect of Various Bases on the 1,4 C $\rightarrow$ O Silyl Migration

\begin{tabular}{|c|c|c|c|c|c|}
\hline \multicolumn{1}{|c|}{} & & & & & \\
\hline
\end{tabular}

a) 3-Hydroxymethylfuran (23\%) was also isolated.

The effect of various solvents and bases on the silyl migration are shown in Table 2. The reaction times varied from 5 minutes in DMF to considerably longer times in THF (16 h) and DME (56h) (entries 1-3); no reaction occurred in diethyl ether (entry 4). ${ }^{4}$ Interestingly, catalytic amounts of sodium hydride $(1 \mathrm{~mol} \%)$ in DMF resulted in complete migration within 15 minutes (entry 5).

Various counterions were also employed. The silyl migration occurred when either sodium or potassium bases $^{5}$ were used (entries 1-7); however, the use of magnesium and lithium bases resulted in only the isolation of starting material(entries 8-10). ${ }^{3 \mathrm{C}}$ These results with various counterions and the rate enhancement observed with sodium ions in DMF (when compared to THF) could be rationalized on the degree of ion pair dissociation. ${ }^{6} \mathrm{~A}$ similar arguement has been proposed to explain the effect of counterions on the rate of reaction of the oxy-Cope reaction.

Surprisingly, the silyl migration of 6 in DMF did not produce any 3-[(t-butyldimethylsilyl)oxymethyl $]-2$ formylfuran 31 (Scheme 2), indicating that a formal C-2 carbanion must not be present during the reaction. ${ }^{7}$ Crossover experiments indicated the $1,4 \mathrm{C} \rightarrow \mathrm{O}$ silyl migration observed herein is an intramolecular process.

SCHEME 2

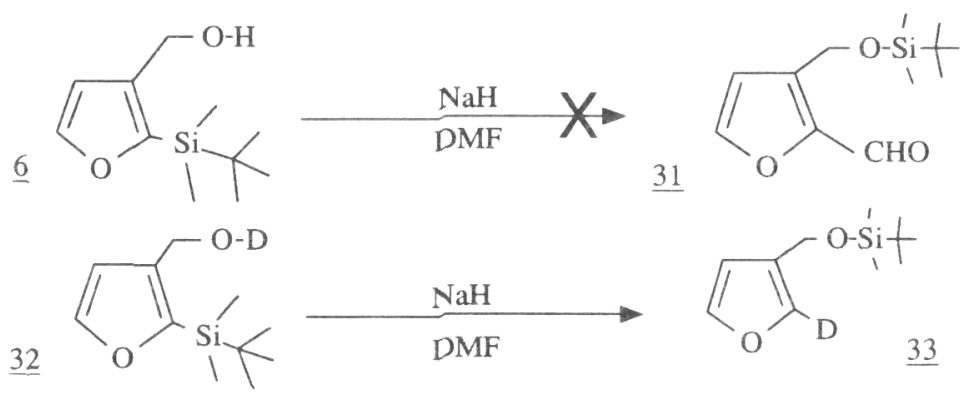


Intermediates involving pentavalent silicon atoms have been postulated in other intramolecular $1, \mathrm{n}$ silyl migrations. ${ }^{3 c, 6,8}$ Such an intermediate could account for the non-reactivity with electrophiles other than protons in this reaction. ${ }^{3 c}$

Finally, it has been postulated that when $1, \mathrm{n}$ silyl rearrangements are performed with catalytic amounts of base in aprotic solvents, the starting material hydroxyl hydrogen atom acts as the proton source. ${ }^{8}$ Indeed, furan $32^{9}$ (Scheme 2) when treated with 1 equivalent of sodium hydride (DMF, $5 \mathrm{~min}$ ) provided 3-[(t-butyldimethylsilyl)oxymethyl]-2-deuteriofuran 33 (96\%); ${ }^{1} \mathrm{H}$ NMR and MS indicated no proton was present in the C-2 position. $^{10}$

Synthetic applications of these rearrangements are currently being investigated.

\section{EXPERIMENTAL}

A general experimental procedure follows. To a solution of a furan-alcohol $(0.27 \mathrm{mmol})$ in DMF $(5.4 \mathrm{~mL})$ at room temperature was added sodium hydride $(1.36 \mathrm{mmol})$ and the mixture stirred 1 hour. Ether $(6 \mathrm{~mL})$ was added followed by the cautious addition of saturated brine. The ether layer was separated, washed with saturated $\mathrm{NaCl}$ (6 x's)and dried $\left(\mathrm{Na}_{2} \mathrm{SO}_{4}\right)$. The ether was removed in vacuo to leave an oil which was distilled. ${ }^{11}$

\section{ACKNOWLEDGEMENTS}

We thank the Natural Sciences and Engineering Research Council of Canada for financial support

\section{REFERENCES and NOTES}

1) Bures, E.J.; Keay, B.A. Tetrahedron Lett., 1987, 28, 5965.

2) Bures, E.J.; Keay, B.A. Tetrahedron Lett., 1988, 29, 1247.

3) a) Isobe, M.; Ichikawa, Y.; Funabashi, Y.; Mio, S.; Goto, T. Tetrahedron, 1986, 42, 2863 and references therein; b) Takeda, T.; Naito, S.; Ando, K.; Fujiwara, T. Bull. Chem. Soc. Jpn., 1983, 56, 967; c) Fleming, I.; Floyd, C.D. J.C.S. Perkin I, 1981, 969; d) Isobe, M.; Kitamura, M.; Goto, T. Tetrahedron Lett., 1980, 21 , 4727; e) Matsuda, I.; Murata, S.; Ishii, Y. J.C.S. Perkin I, 1979, 26; f) Matsuda, I.; Murata, S.; Izumi, Y. Bull. Chem. Soc. Jpn., 1979, 52, 2389; g) Isobe, M.; Kitamura, M.; Goto, T. Tetrahedron Lett., 1979, 20, 3465; h) Woodbury, R.P.; Rathke, M.W. J. Org. Chem., 1979, 43, 1947.

4) Other 1,4 C $\rightarrow \mathrm{O}$ silyl migrations involving sodium ions in diethyl ether have been reported not to proceed. See reference $3 c$ above and reference 6 therein.

5) Potassium hydride was not used in DMF as it is known to reduce DMF to dimethylamine after hydrolysis. Brown, C.A. J. Org. Chem. 1974, 39, 3913.

6) Evans, D.A.; Golob, A.M. J. Am. Chem. Soc., 1975, 97, 4765; Magnera, T.F.; Caldwell, G.; Sunner, J.; Ikuta, S.; Kebarle, P. J. Amer. Chem. Soc., 1984, 106, 6140.

7) It is well known that furaldehyde can be prepared by lithiating furan at the C-2 position followed by a DMF quench. See: Gschwend, H.W.; Rodriguez, H.R. Organic Reactions, 1979, 26, 1.

8) Brook, A.G.; Bassindale, A.R. Rearrangements in Ground and Excited States, 1980, 2, 149.

9) Compound 32 was prepared by stirring compound 6 in dry DMF containing 2 equivalents of $\mathrm{D}_{2} \mathrm{O}$ (under argon) for 15 minutes. The DMF solution was then passed through a plug of anhydrous $\mathrm{MgSO}_{4}$ (to remove the excess $\mathrm{D}_{2} \mathrm{O}$ and $\mathrm{HOD}$ ) directly into a reaction flask containing $\mathrm{NaH}$ and $\mathrm{DMF}$.

10) Brook, A.G.; Chrusciel, J.J. Organometallics, 1984, 3, 1317.

11) All new compounds provided analytical and/or spectroscopic data consistent with their structures.

(Received in USA 15 November 1988) 